Commentary

\title{
Stronger is not always better: Could a bodybuilding dietary supplement lead to ALS?
}

\author{
Marin Manuel $^{\mathrm{a}, *}$, C.J. Heckman ${ }^{\mathrm{a}, \mathrm{b}}$ \\ a Northwestern University, Department of Physiology, 303 E Chicago Ave, Chicago, IL 60611, USA \\ b Northwestern University, Deparment of Physical Medicine and Rehabilitation, 303 E Chicago Ave, Chicago, IL 60611, USA
}

\section{A R T I C L E I N F O}

\section{Article history:}

Received 5 November 2010

Revised 7 December 2010

Accepted 8 December 2010

Available online 15 December 2010

\section{Keywords:}

Hyperexcitability

BCAA

Environmental factors in ALS

Electrophysiology

Persistent sodium current

G93A

Despite having been formally described almost 150 years ago (Charcot and Joffroy, 1869), the causes of Amyotrophic Lateral Sclerosis (ALS) remain a mystery. ALS is one of the most common neuromuscular diseases worldwide, and is characterized by the degeneration of both upper and lower motoneurons. Most of the cases are sporadic (i.e. affecting individuals seemingly randomly), and only about $10 \%$ of cases can be traced to a family history. Even in sporadic cases, a (spontaneous) genetic cause cannot be ruled out, but most experts would argue today that the disease is probably caused by a combination of genetic predispositions and environmental factors. Indeed, it has been hypothesized that toxins, pollutants or even diet could induce ALS in some populations. For example, an indigenous population on the island of Guam, in the Pacific, was found to have an unusually high incidence of ALS (at one time almost 100 times higher than the general population, although it has been declining in the past decades) (Reed et al., 1987; Steele and McGeer, 2008). Several hypotheses have been proposed to explain this high risk, including trace amounts of rare minerals in their environment (Purdey, 2004), or more recently their diet enriched in a special type of non-protein amino acid, beta-methylamino-L-alanine, found in the seeds of an indigenous tree (Bradley and Mash, 2009; Cox and Sacks, 2002).

In the November 2010 issue of Experimental Neurology, Carunchio et al. explore the possible role in ALS of another type of amino acid, the branched-chain amino acids (BCAAs), which are amino acids with an aliphatic side chain, and are commonly used as dietary supplements

\footnotetext{
* Corresponding author. Northwestern University, Department of Physiology, 303 E Chicago Ave, Chicago, IL 60611, USA.

E-mail address: marin.manuel@northwestern.edu (M. Manuel).
}

by athletes to stimulate muscle growth and recovery after intense exercise (Ohtani et al., 2006). BCAAs have been suggested to be the cause of a high incidence of ALS among professional American football players (Abel, 2007) and Italian soccer players (Armon, 2007; Belli and Vanacore, 2005; Beretta et al., 2003; Vanacore et al., 2006). Carunchio et al. compared the effect of a diet enriched in BCAAs on mouse cortical motoneurons (the population of cortical neurons that command the spinal motoneurons, and which are specifically affected along with spinal motoneurons, in ALS) to the effect of a genetic mutation causing ALS (the substitution of a glycine for an alanine in position 93 of the human SOD1 gene, a.k.a. "G93A") in mice. This group has previously shown that, in the cortical motoneurons of the G93A mouse model, the persistent sodium current ( $I_{N a P}$, a subtype of sodium current that inactivates very slowly) is upregulated compared to control mice. This leads to a hyperexcitability of the cells: they fire more action potentials than control cells for the same amount of excitation (Pieri et al., 2009). In the present work, Carunchio et al. show that a diet enriched in BCAAs also induced a hyperexcitability of the cortical motoneurons. This effect was dose dependent and specific to BCAAs, as diet enriched with non-branched-chained amino acids such as alanine or phenylalanine did not alter the excitability of the cells. They go on to show that the hyperexcitability is probably mediated by an up-regulation of $I_{N a P}$. An especially important result was the demonstration that rapamycin, an inhibitor of the mTOR pathway, can revert hyperexcitability in animals fed with a BCAA enriched diet as well as in G93A animals. MTOR is a protein kinase that controls protein synthesis, cell growth and proliferation (Sandsmark et al., 2007; Sarbassov et al., 2005), and its activity is regulated by nutrients, such as BCAAs (Avruch et al., 2001). The fact that rapamycin can lower the excitability of G93A cells but not control cells suggests that the hyperexcitability described in cortical motoneurons of G93A mice could be a consequence of the activation of the MTOR pathway.

Upregulation of $I_{\mathrm{NaP}}$ and neuronal hyperexcitability appear to be hallmarks of ALS. Signs of hyperexcitability in ALS have been described throughout the CNS (e.g. in the motor cortex (Pieri et al., 2009), the hypoglossal nucleus (van Zundert et al., 2008) and the spinal cord (Jiang et al., 2009; Kuo et al., 2004; Pambo-Pambo et al., 2009; Quinlan et al., 2009)), and these signs appear very early in the disease progression, as early as 5-10 days of birth in mouse models (Pambo-Pambo et al., 2009; Quinlan et al., 2009; van Zundert et al., 2008). Changes in excitability were also observed in human patients before symptom onset (Vucic et al., 2008). Overall, these observations tend to support the "excitotoxicity" hypothesis proposed as a mechanism of cell death in ALS (reviewed, for example, in Grosskreutz et al., 2010; Kiernan, 2009). Excitotoxicity refers to a 
pathological state in which a cell experiences an overload of intracellular calcium, which triggers apoptotic pathways. In a hyperexcitable environment, more calcium enters the cells: firstly, cells fire at higher frequency, which leads to an over-activation of their voltage-sensitive calcium channels, and thus a strong entry of calcium. Secondly, hyperexcitable presynaptic cells release more glutamate, which in turn over-activates glutamate receptors on both sides of the synaptic cleft, some of which are calcium permeable. Motoneurons are especially vulnerable to excitotoxicity as they have low calcium buffering capabilities (Lips et al., 2000; Palecek et al., 1999; Vanselow and Keller, 2000), they express calcium permeable isoforms of the AMPA receptors (Greig et al., 2000; Van Damme et al., 2002; Van den Bosch et al., 2002; Van den Bosch et al., 2000), and they possess strong low-voltage activated (L-type) calcium currents (Carlin et al., 2000a,b; Li et al., 2004). Furthermore, the only FDA approved drug currently used for the treatment of ALS is riluzole, which lowers the excitability of the cells through various pathways (see Cheah et al., 2010 for a review). Riluzole was shown to be an antagonist of NMDA receptors (Debono et al., 1993, Estevez et al., 1995, Malgouris et al., 1994), an antagonist of AMPA/kainate receptors (Albo et al., 2004; Debono et al., 1993), a blocker of voltage activated calcium channels (Siniscalchi et al., 1997; Stevenson et al., 2009), and a blocker of voltage activated sodium channels. However, at concentrations achieved by oral administration (1-2 $\mu \mathrm{M}$, Le Liboux et al., 1997), riluzole is considered to be a fairly specific blocker of $I_{N a P}$, with less effect on the transient sodium current (Urbani and Belluzzi, 2000), and an inhibitor of vesicular release of glutamate (Cheramy et al., 1992; Doble, 1996; Martin et al., 1993). However, riluzole has only a modest effect on the survivability of patients with ALS (9\% in the probability of surviving one year, i.e. an increase of survival by two to three months) (Miller et al., 2007).

Carunchio et al. propose a new therapeutic approach using rapamycin. Inhibitors of mTOR, such as rapamycin (which are currently used to prevent organ transplant rejections), have been shown to prolong the lifespan of mice (Harrison et al., 2009), and might have therapeutic effects in the treatment of cancers (Faivre et al., 2006), autism (Ehninger et al., 2008), and Alzheimer's (Spilman et al., 2010). Carunchio et al. show that rapamycin might be able, not only to reduce the excitability of motoneurons, but also to alter the activity of at least one transcription factor. They show that the level of phosphorylation of p70S6, a protein known to regulate cell growth and protein synthesis, was increased in animals fed with BCAAs and in G93A mice, and that this increased phosphorylation was reverted by rapamycin in both populations. As such, it appears that rapamycin could act at several levels in the cascade of events leading to the neuronal hyperexcitability, and thus could provide better outcome for the patients.

The similar increase in excitability in G93A and BCAA-treated neurons is striking and might reflect a common mechanism. However, the link between hyperexcitability and disease remains to be established. Whether the increased excitability is responsible for the degeneration or a non-specific consequence of cell damage is still heavily debated. This point is especially important considering that ALS is a non-cell-autonomous disease, that is to say that the toxic property leading to the disease must be present in multiple cell types, besides motoneurons, to reach the pathological state (for reviews, see Boillée et al., 2006a; Ilieva et al., 2009). Evidence supporting this hypothesis was initially produced by the selective expression of the mutant SOD1 gene only in motoneurons (Lino et al., 2002; Pramatarova et al., 2001), or only in astrocytes (Gong et al., 2000). Neither of these constructs led to motoneuron degeneration or death. Further evidence has been provided by the use of a genetic construct in which the mutant SOD1 gene could be selectively excised in various cell types (Boillée et al., 2006b). Specific excision of the mutant SOD1 gene in motoneurons delayed the onset of the disease and slowed the early stages of the disease, while excision of the same gene specifically in microglia slowed the later stages of the disease. The role of the muscles in the disease is still unclear, but it is well documented that one of the earliest events in ALS is the withdrawal of the motor axons from the neuromuscular junction (NMJ) (Balice-Gordon et al., 2000; Fischer et al., 2004; Frey et al., 2000; Hegedus et al., 2007, 2008; Parkhouse et al., 2008; Pun et al., 2006). The hyperexcitability seen in the disease could thus be a direct effect on the neurons, or an indirect consequence of damages to neighboring cell types. Although single cell electrophysiology experiments (as used in the present article by Carunchio et al.) are essential for the study of the physiopathology of ALS, it is of critical importance to couple them with studies conducted in vivo, using behavioral and electrophysiological tools and techniques. Indeed, the potential neuroprotective impact of reverting the hyperexcitability remains to be established, especially considering that riluzole has such a modest effect on the survivability of patients.

The recent development of an in vivo adult mouse preparation by our group (Manuel et al., 2009) opens up the possibility of studying the role of the NMJ in ALS by testing the behavior of motoneurons and muscles fibers (both independently and together) during the progression of the disease. Such studies are necessary given the debate in the literature regarding whether ALS progresses in a retrograde fashion ("dying back", i.e. from the periphery to the CNS, and from lower motoneurons to upper motoneurons) or in an anterograde fashion ("dying forward", i.e. from cortex to spinal cord, to periphery). The dying back hypothesis rests on the observations that, in ALS mice models, as mentioned above, NMJs disconnect at an early stage of the disease, well before the spinal motoneurons start to degenerate, and that changes in the biochemistry of hind limb muscles might happen before the retraction of the NMJs (Park and Vincent, 2008). Furthermore, neuroimaging experiments conducted in human patients revealed morphological alteration in the distal portions of the cortico-spinal tracts (Ellis et al., 2001; Karlsborg et al., 2004; Nair et al., 2010). On the other hand, the fact that cortical motoneurons are hyperexcitable in presymptomatic stages of the disease (Mills and Nithi, 1997; Pieri et al., 2009; Vucic et al., Zanette et al., 2002), and the observation of early morphological perturbations in the cortex of ALS patients (Ince, 2000; Sasaki and Iwata, 1999) might indicate a dying forward mechanism (see Eisen and Weber, 2001 for a review).

Whichever the case, dying back or dying forward, the impact of environmental factors on ALS needs to be carefully studied. The work by Carunchio et al. in the November 2010 issue of Experimental Neurology provides a significant breakthrough for the potential role of such a toxin (BCAAs in this case) in sporadic ALS, as well as a promising new therapeutic target, the mTOR pathway. Yet the link between BCAAs and ALS remains to be fully established. The present work shows that BCAAs can induce a hyperexcitability similar to the one observed in G93A mice (Pieri et al., 2009), but they did not show if a BCAA-enriched diet, given to mice over a prolonged period, induces ALS-like symptoms. More experiments are needed to establish if the hyperexcitability of upper and lower motoneurons is a direct consequence of the disease, or a compensatory mechanism of the CNS. These experiments must combine electrophysiology at the cellular level with behavioral studies to assess how drugs that can alter the excitability of the motoneurons to modify the course of the disease.

\section{References}

Abel, E.L., 2007. Football increases the risk for Lou Gehrig's disease, amyotrophic lateral sclerosis. Percept. Mot. Skills 104, 1251-1254.

Albo, F., Pieri, M., Zona, C., 2004. Modulation of AMPA receptors in spinal motor neurons by the neuroprotective agent riluzole. J. Neurosci. Res. 78, 200-207.

Armon, C., 2007. Sports and trauma in amyotrophic lateral sclerosis revisited. J. Neurol Sci. 262, 45-53.

Avruch, J., Belham, C., Weng, Q., Hara, K., Yonezawa, K., 2001. The p70 S6 kinase integrates nutrient and growth signals to control translational capacity. Prog. Mol. Subcell. Biol. 26, 115-154. 
Balice-Gordon, R.J., Smith, D.B., Goldman, J., Cork, L.C., Shirley, A., Cope, T.C., Pinter, M.J 2000. Functional motor unit failure precedes neuromuscular degeneration in canine motor neuron disease. Ann. Neurol. 47, 596-605.

Belli, S., Vanacore, N., 2005. Proportionate mortality of Italian soccer players: is amyotrophic lateral sclerosis an occupational disease? Eur. J. Epidemiol. 20, 237-242.

Beretta, S., Carri, M.T., Beghi, E., Chio, A., Ferrarese, C., 2003. The sinister side of Italian soccer. Lancet Neurol. 2, 656-657.

Boillée, S., Vande Velde, C., Cleveland, D.W., 2006a. ALS: a disease of motor neurons and their nonneuronal neighbors. Neuron 52, 39-59.

Boillée, S., Yamanaka, K., Lobsiger, C.S., Copeland, N.G., Jenkins, N.A., Kassiotis, G., Kollias, G., Cleveland, D.W., 2006b. Onset and progression in inherited ALS determined by motor neurons and microglia. Science 312, 1389-1392.

Bradley, W.G., Mash, D.C., 2009. Beyond Guam: the cyanobacteria/BMAA hypothesis of the cause of ALS and other neurodegenerative diseases. Amyotroph. Lateral Scler. 10 (Suppl 2), 7-20.

Carlin, K.P., Jiang, Z., Brownstone, R.M., 2000a. Characterization of calcium currents in functionally mature mouse spinal motoneurons. Eur. J. Neurosci. 12, 1624-1634.

Carlin, K.P., Jones, K.E., Jiang, Z., Jordan, L.M., Brownstone, R.M., 2000b. Dendritic L-type calcium currents in mouse spinal motoneurons: implications for bistability. Eur. J. Neurosci. 12, 1635-1646.

Charcot, J., Joffroy, A., 1869. Deux cas d'atrophie musculaire progressive avec lésions de la substance grise et des faisceaux antéro-latéraux de la moelle épinière. Arch. Physiol. Neurol. Pathol. 2, 744.

Cheah, B.C., Vucic, S., Krishnan, A.V., Kiernan, M.C., 2010. Riluzole, neuroprotection and amyotrophic lateral sclerosis. Curr. Med. Chem. 17, 1942-1199.

Cheramy, A., Barbeito, L., Godeheu, G., Glowinski, J., 1992. Riluzole inhibits the release of glutamate in the caudate nucleus of the cat in vivo. Neurosci. Lett. 147, 209-212.

Cox, P.A., Sacks, O.W., 2002. Cycad neurotoxins, consumption of flying foxes, and ALS PDC disease in Guam. Neurology 58, 956-959.

Debono, M.W., Le Guern, J., Canton, T., Doble, A., Pradier, L., 1993. Inhibition by riluzole of electrophysiological responses mediated by rat kainate and NMDA receptors expressed in Xenopus oocytes. Eur. J. Pharmacol. 235, 283-289.

Doble, A., 1996. The pharmacology and mechanism of action of riluzole. Neurology 47 S233-S241.

Ehninger, D., Han, S., Shilyansky, C., Zhou, Y., Li, W., Kwiatkowski, D.J., Ramesh, V., Silva A.J., 2008. Reversal of learning deficits in a Tsc2+/- mouse model of tuberous sclerosis. Nat. Med. 14, 843-848.

Eisen, A., Weber, M., 2001. The motor cortex and amyotrophic lateral sclerosis. Muscle Nerve 24, 564-573.

Ellis, C.M., Suckling, J., Amaro, E., Bullmore, E.T., Simmons, A., Williams, S.C., Leigh, P.N., 2001. Volumetric analysis reveals corticospinal tract degeneration and extramotor involvement in ALS. Neurology 57, 1571-1578.

Estevez, A.G., Stutzmann, J.M., Barbeito, L., 1995. Protective effect of riluzole on excitatory amino acid-mediated neurotoxicity in motoneuron-enriched cultures. Eur. J. Pharmacol. 280, 47-53.

Faivre, S., Kroemer, G., Raymond, E., 2006. Current development of mTOR inhibitors as anticancer agents. Nat. Rev. Drug Discov. 5, 671-688.

Fischer, L.R., Culver, D.G., Tennant, P., Davis, A.A., Wang, M., Castellano-Sanchez, A., Khan, J., Polak, M.A., Glass, J.D., 2004. Amyotrophic lateral sclerosis is a distal axonopathy: evidence in mice and man. Exp. Neurol. 185, 232-240.

Frey, D., Schneider, C., Xu, L., Borg, J., Spooren, W., Caroni, P., 2000. Early and selective loss of neuromuscular synapse subtypes with low sprouting competence in motoneuron diseases. J. Neurosci. 20, 2534-2542.

Gong, Y.H., Parsadanian, A.S., Andreeva, A., Snider, W.D., Elliott, J.L., 2000. Restricted expression of G86R $\mathrm{Cu} / \mathrm{Zn}$ superoxide dismutase in astrocytes results in astrocytosis but does not cause motoneuron degeneration. J. Neurosci. 20, 660-665.

Greig, A., Donevan, S.D., Mujtaba, T.J., Parks, T.N., Rao, M.S., 2000. Characterization of the AMPA-activated receptors present on motoneurons. J. Neurochem. 74, 179-191.

Grosskreutz, J., Van den Bosch, L., Keller, B.U., 2010. Calcium dysregulation in amyotrophic lateral sclerosis. Cell Calcium 47, 165-174.

Harrison, D.E., Strong, R., Sharp, Z.D., Nelson, J.F., Astle, C.M., Flurkey, K., Nadon, N.L., Wilkinson, J.E., Frenkel, K., Carter, C.S., Pahor, M., Javors, M.A., Fernandez, E., Miller, R.A., 2009. Rapamycin fed late in life extends lifespan in genetically heterogeneous mice. Nature 460, 392-395.

Hegedus, J., Putman, C.T., Gordon, T., 2007. Time course of preferential motor unit loss in the SOD1 G93A mouse model of amyotrophic lateral sclerosis. Neurobiol. Dis. 28, $154-164$

Hegedus, J., Putman, C.T., Tyreman, N., Gordon, T., 2008. Preferential motor unit loss in the SOD1 G93A transgenic mouse model of amyotrophic lateral sclerosis. J. Physiol. 586, 3337-3351.

Ilieva, H., Polymenidou, M., Cleveland, D.W., 2009. Non-cell autonomous toxicity in neurodegenerative disorders: ALS and beyond. J. Cell Biol. 187, 761-772.

Ince, P.G., 2000. Neuropathology. In: Brown, R., Meininger, V., Swash, M. (Eds.), Amyotrophic Lateral Sclerosis. Martin Dunitz, London.

Jiang, M., Schuster, J.E., Fu, R., Siddique, T., Heckman, C.J., 2009. Progressive changes in synaptic inputs to motoneurons in adult sacral spinal cord of a mouse model of amyotrophic lateral sclerosis. J. Neurosci. 29, 15031-15038.

Karlsborg, M., Rosenbaum, S., Wiegell, M., Simonsen, H., Larsson, H., Werdelin, L, Gredal, O., 2004. Corticospinal tract degeneration and possible pathogenesis in ALS evaluated by MR diffusion tensor imaging. Amyotroph. Lateral Scler. Other Mot Neuron Disord. 5, 136-140.

Kiernan, M.C., 2009. Hyperexcitability, persistent $\mathrm{Na}+$ conductances and neurodegeneration in amyotrophic lateral sclerosis. Exp. Neurol. 218, 1-4.

Kuo, J.J., Schonewille, M., Siddique, T., Schults, A.N.A., Fu, R., Bär, P.R., Anelli, R. Heckman, C.J., Kroese, A.B.A., 2004. Hyperexcitability of cultured spinal motoneurons from presymptomatic ALS mice. J. Neurophysiol. 91, 571-575.
Le Liboux, A., Lefebvre, P., Le Roux, Y., Truffinet, P., Aubeneau, M., Kirkesseli, S., Montay, G., 1997. Single- and multiple-dose pharmacokinetics of riluzole in white subjects. J. Clin. Pharmacol. 37, 820-827.

Li, Y., Gorassini, M.A., Bennett, D.J., 2004. Role of persistent sodium and calcium currents in motoneuron firing and spasticity in chronic spinal rats. J. Neurophysiol. 91, 767-783.

Lino, M.M., Schneider, C., Caroni, P., 2002. Accumulation of SOD1 mutants in postnatal motoneurons does not cause motoneuron pathology or motoneuron disease. J. Neurosci. 22, 4825-4832.

Lips, J., de Haan, P., Bodewits, P., Vanicky, I., Dzoljic, M., Jacobs, M.J., Kalkman, C.J., 2000. Neuroprotective effects of riluzole and ketamine during transient spinal cord ischemia in the rabbit. Anesthesiology 93, 1303-1311.

Malgouris, C., Daniel, M., Doble, A., 1994. Neuroprotective effects of riluzole on Nmethyl-D-aspartate- or veratridine-induced neurotoxicity in rat hippocampal slices. Neurosci. Lett. 177, 95-99.

Manuel, M., Iglesias, C., Donnet, M., Leroy, F., Heckman, C.J., Zytnicki, D., 2009. Fast kinetics, high-frequency oscillations, and subprimary firing range in adult mouse spinal motoneurons. J. Neurosci. 29, 11246-11256.

Martin, D., Thompson, M.A., Nadler, J.V., 1993. The neuroprotective agent riluzole inhibits release of glutamate and aspartate from slices of hippocampal area CA1. Eur. J. Pharmacol. 250, 473-476.

Miller, R.G., Mitchell, J.D., Lyon, M., Moore, D.H., 2007. Riluzole for amyotrophic lateral sclerosis (ALS)/motor neuron disease (MND). Cochrane Database Syst. Rev. CD001447.

Mills, K.R., Nithi, K.A., 1997. Corticomotor threshold is reduced in early sporadic amyotrophic lateral sclerosis. Muscle Nerve 20,1137-1141.

Nair, G., Carew, J.D., Usher, S., Lu, D., Hu, X.P., Benatar, M., 2010. Diffusion tensor imaging reveals regional differences in the cervical spinal cord in amyotrophic lateral sclerosis. Neuroimage 53, 576-583.

Ohtani, M., Sugita, M., Maruyama, K., 2006. Amino acid mixture improves training efficiency in athletes. J. Nutr. 136, 538S-543S.

Palecek, J., Lips, M.B., Keller, B.U., 1999. Calcium dynamics and buffering in motoneurones of the mouse spinal cord. J. Physiol. 520 (Pt 2), 485-502.

Pambo-Pambo, A., Durand, J., Gueritaud, J., 2009. Early excitability changes in lumbar motoneurons of transgenic SOD1G85R and SOD1G93A-Low mice. J. Neurophysiol. 102 (6), 3627-3642.

Park, K.H.J., Vincent, I., 2008. Presymptomatic biochemical changes in hindlimb muscle of G93A human $\mathrm{Cu} / \mathrm{Zn}$ superoxide dismutase 1 transgenic mouse model of amyotrophic lateral sclerosis. Biochim. Biophys. Acta 1782, 462-468.

Parkhouse, W.S., Cunningham, L., McFee, I., Miller, J.M.L., Whitney, D., Pelech, S.L., Krieger, C., 2008. Neuromuscular dysfunction in the mutant superoxide dismutase mouse model of amyotrophic lateral sclerosis. Amyotroph. Lateral Scler. 9, 24-34.

Pieri, M. Carunchio, I., Curcio, L., Mercuri, N.B., Zona, C., 2009. Increased persistent sodium current determines cortical hyperexcitability in a genetic model of amyotrophic lateral sclerosis. Exp. Neurol. 215, 368-379.

Pramatarova, A., Laganiere, J., Roussel, J., Brisebois, K., Rouleau, G.A., 2001. Neuronspecific expression of mutant superoxide dismutase 1 in transgenic mice does not lead to motor impairment. J. Neurosci. 21, 3369-3374.

Pun, S., Santos, A.F., Saxena, S., Xu, L., Caroni, P., 2006. Selective vulnerability and pruning of phasic motoneuron axons in motoneuron disease alleviated by CNTF. Nat. Neurosci. 9, 408-419.

Purdey, M., 2004. Elevated levels of ferrimagnetic metals in foodchains supporting the Guam cluster of neurodegeneration: do metal nucleated crystal contaminants [corrected] evoke magnetic fields that initiate the progressive pathogenesis of neurodegeneration? Med. Hypotheses 63, 793-809.

Quinlan, K.A., ElBasiouny, S.M., Heckman, C.J., 2009. Increased excitability in juvenile SOD1 motoneurons Program No. 304.11. 2009 Neuroscience Meeting Planner. Society for Neuroscience, Chicago, IL. 2009. Online

Reed, D., Labarthe, D., Chen, K.M., Stallones, R., 1987. A cohort study of amyotrophic lateral sclerosis and parkinsonism-dementia on Guam and Rota. Am. J. Epidemiol. $125,92-100$.

Sandsmark, D.K., Pelletier, C., Weber, J.D., Gutmann, D.H., 2007. Mammalian target of rapamycin: master regulator of cell growth in the nervous system. Histol. Histopathol. 22, 895-903.

Sarbassov, D.D., Ali, S.M., Sabatini, D.M., 2005. Growing roles for the mTOR pathway. Curr. Opin. Cell Biol. 17, 596-603.

Sasaki, S., Iwata, M., 1999. Ultrastructural change of synapses of Betz cells in patients with amyotrophic lateral sclerosis. Neurosci. Lett. 268, 29-32.

Siniscalchi, A., Bonci, A., Mercuri, N.B., Bernardi, G., 1997. Effects of riluzole on rat cortical neurones: an in vitro electrophysiological study. Br. J. Pharmacol. 120, 225-230.

Spilman, P., Podlutskaya, N., Hart, M.J., Debnath, J., Gorostiza, O., Bredesen, D., Richardson, A., Strong, R., Galvan, V., 2010. Inhibition of mTOR by rapamycin abolishes cognitive deficits and reduces amyloid-beta levels in a mouse model of Alzheimer's disease. PLoS ONE 5, e9979.

Steele, J.C., McGeer, P.L., 2008. The ALS/PDC syndrome of Guam and the cycad hypothesis. Neurology 70, 1984-1990.

Stevenson, A., Yates, D.M., Manser, C., De Vos, K.J., Vagnoni, A., Leigh, P.N., McLoughlin, D.M., Miller, C.C., 2009. Riluzole protects against glutamate-induced slowing of neurofilament axonal transport. Neurosci. Lett. 454, 161-164.

Urbani, A., Belluzzi, O., 2000. Riluzole inhibits the persistent sodium current in mammalian CNS neurons. Eur. J. Neurosci. 12, 3567-3574.

Van Damme, P., Van den Bosch, L., Van Houtte, E., Callewaert, G., Robberecht, W., 2002. GluR2-dependent properties of AMPA receptors determine the selective vulnerability of motor neurons to excitotoxicity. J. Neurophysiol. 88, 1279-1287.

Van den Bosch, L., Van Damme, P., Vleminckx, V., Van Houtte, E., Lemmens, G., Missiaen, L., Callewaert, G., Robberecht, W., 2002. An alpha-mercaptoacrylic acid derivative 
(PD150606) inhibits selective motor neuron death via inhibition of kainateinduced $\mathrm{Ca} 2+$ influx and not via calpain inhibition. Neuropharmacology 42, 706-713.

Van den Bosch, L., Vandenberghe, W., Klaassen, H., Van Houtte, E., Robberecht, W., 2000.

$\mathrm{Ca}(2+)$-permeable AMPA receptors and selective vulnerability of motor neurons. J. Neurol. Sci. 180, 29-34.

van Zundert, B., Peuscher, M.H., Hynynen, M., Chen, A., Neve, R.L., Brown, R.H., Constantine-Paton, M., Bellingham, M.C., 2008. Neonatal neuronal circuitry shows hyperexcitable disturbance in a mouse model of the adult-onset neurodegenerative disease amyotrophic lateral sclerosis. J. Neurosci. 28, 10864-10874.
Vanacore, N., Binazzi, A., Bottazzi, M., Belli, S., 2006. Amyotrophic lateral sclerosis in an Italian professional soccer player. Parkinsonism Relat. Disord. 12, 327-329.

Vanselow, B.K., Keller, B.U., 2000. Calcium dynamics and buffering in oculomotor neurones from mouse that are particularly resistant during amyotrophic lateral sclerosis (ALS)-related motoneurone disease. J. Physiol. 525 (Pt 2), 433-445.

Vucic, S., Nicholson, G.A., Kiernan, M.C., 2008. Cortical hyperexcitability may precede the onset of familial amyotrophic lateral sclerosis. Brain 131, 1540-1550.

Zanette, G., Tamburin, S., Manganotti, P., Refatti, N., Forgione, A., Rizzuto, N., 2002. Different mechanisms contribute to motor cortex hyperexcitability in amyotrophic lateral sclerosis. Clin. Neurophysiol. 113, 1688-1697. 